\title{
SAFETY ENVIRONMENTAL ASSESSMENT IN THE BLAST FURNACE SECTION
}

\author{
Adrian VASILIU \\ "Dunarea de Jos" University of Galati, Romania \\ e-mail: avasiliu@ugal.ro
}

\begin{abstract}
Assessing the safety climate used as a practical means to a relevant determinant problem regarding the safety and health in the work in the organization. The instruments applied are collected through questionnaires, group discussions or interviews and observations. The aim of the study is to determine a working climate at a steel section of elaboration (furnace) and a climatic definition of administration (management, health communication and safety).
\end{abstract}

KEYWORDS: blast furnace section, safety climate, occupational management

\section{Introduction}

The steel industry is one of the industrial activities, quite complex, with production costs, and high professional risks. This is how global trends of implementation in production technologies, raw materials, characterized by efficiency and performance have occurred and are currently manifesting, with the ultimate goal of reducing specific fuel consumption and energy losses, which will affect as little as possible the environment and which does not lead to occupational accidents and diseases. As the number of people in charge increased, the number and importance of managerial functions increased, and the structure organized to make the managerial act more efficient, bears the name of managerial organization.

The term "safety climate" has been used as a multi-domain factor, having an important role in the safety of the work environment, and represents the interaction between the safety climate and the security behaviour [3].

The climate of safety measures and describes the common perception of the employees on how to manage safety in a working environment in a certain period. Depending on priorities such as production and quality, perceptions provide an index to prioritize safety within an organization. The study of the safety climate has been presented as an important index in the health and safety problems of the working environments and the corrective actions thereof have a considerable effect on the efficiency of the work of the workers and the successful control over the accidents in the working environment [3].
Security behaviour is considered as another important index in the health and safety problems of the working environment, and it has an instrument for implementing and reforming the results of the effects of creating efficiency in the functioning of the employees and the successful control of accidents that could have environments for work [3].

\section{Objectives}

The aim of the study is to determine the climate and safety profile in a steel section for the development of the first fusion furnace and to define the safety climate (management, communication for health and safety at work, safety priority). Ten aspects of safety aspects are evaluated, including the relationship of the organization and the manager's commitment, the role of the process leader, the role of the staff, the effect of the colleague, the competence of the worker, the risky behaviour, the obstacles in the safety behaviour, the work permit and the incident and pseudo incidents report in the section. ovens. The result indicated that there is a significant difference in the safety climate between the different working groups.

\section{Theoretical considerations}

A Quality Management System (SMC) is a system through which an organization intends to eliminate or at least reduce non-conformities to the technical specifications, the respective industrial standards, in the most efficient and effective way possible. In other words, a SMC represents a set of 
policies, processes and procedures necessary for planning and execution in the area of basic activities. The Likert scale is an ordinal scale, which is used to evaluate multiple rating statements between a "total agreement" and a "total disagree". The number of steps of the ladder is one and the same for all statements about the phenomenon (five steps). For the processing and interpretation of the data of the 5 levels (Table 1) of the scale will be assigned scores [2].

Table 1. Assessing the importance of values

\begin{tabular}{|c|c|c|c|c|c|}
\hline $\begin{array}{c}\text { Question } \\
\text { evaluation }\end{array}$ & $\begin{array}{c}\text { Disagree } \\
\text { Total }\end{array}$ & Disagree & $\begin{array}{c}\text { No Agreement } \\
\text { / Disagree }\end{array}$ & Agreement & $\begin{array}{c}\text { Agreement } \\
\text { Total }\end{array}$ \\
\hline Scores & -2 & -1 & 0 & +1 & +2 \\
\hline
\end{tabular}

After completing the questionnaire, each article can be analysed separately or, in some cases, responses to an article can be summed to create a score for a group of articles. Therefore, the Likert scale is often called summative scale. The score obtained by the subject is calculated by making the algebraic sum [4].

Data processing is performed in the same way as in the case of Semantic Differential. The average scores for each statement are calculated on a scale from (-2) total disagreement to (2) total agreement.

The total score represents the arithmetic mean of the calculated scores:

$$
S_{i}=\frac{1}{n} \sum x_{i}
$$

where:

$x_{1}, x_{2} \ldots, x_{m}$ is the possible values of characteristic $\mathrm{X}$ (scale of values of characteristic $\mathrm{X}$ );

The relative frequencies, expressed as a percentage, are also called percentage frequencies. They are calculated according to the formula [4]:

$$
f_{i}=\frac{n_{i}}{n} \cdot 100[\%]
$$

where:

$f_{i}$ is the relative frequency of a value [\%];

$n$ - number of subjects investigated;

$n_{1}, n_{2} \ldots n_{i}$ - number of subjects, corresponding to the investigated feature.

The cumulative frequency is the percentage of individuals that do find up to or below a step (value) of the scale. She is calculated according to the formula [4]:

$$
\begin{gathered}
F_{i}=\frac{n_{1}+n_{2}+n_{3}+\cdots+n_{i}}{n} \cdot 100 \quad[\%] \\
F_{i}=f_{1}+f_{2}+f_{3}+\cdots+f_{i}
\end{gathered}
$$

where:

$F_{i}$ is the cumulative frequency [\%];
The score obtained by the subject is calculated by making the algebraic sum. Frequency distributions can also be represented graphically, in form of bar charts, circular charts, radar, etc.

The values of the studied characteristics, collected from the analysed subjects, represent some statistical data (concrete sizes, determined by counting, measuring, etc.), which are grouped in the so-called databases.

\section{Material and methods}

The security climate can be measured in several ways, depending on the needs and capacity of an organization. The tool can be used to examine the climate or safety situation in an organization.

For this reason, the data are obtained through three separate and independent sources (questionnaire, face-to-face interviews and group discussions, observation) and are used in the evaluation $[5,6]$.

Qualitative methods can be classified as follows:

- questionnaire is defined as a list of questions addressed to employees, made up in order to obtain, based on the answers given, information on a problem.

- observation - online collection of information on events, phenomena, objects, persons, etc.;

- interview - discussion that involves the use of an interview guide, unstructured or semi-structured, applied to individuals, with manoeuvring possibilities.

The issues of safety aspects are evaluated, including the relationship of the organization and the manager's commitment, the role of the trial leader, the role of the staff, the effect of the colleague, the competence of the worker, the obstacles in the safety behaviour, the work permit and the incident report and the pseudo incidents in the furnace section.

The questionnaire was established based on documentation, to measure the credibility or validity of the content (Table 2).

After completing the questionnaire, each element (question) is analysed separately. Although 
there is an ordered relationship by category sets, there is no indication of real differences between categories.

\section{Table 2}

\begin{tabular}{|l|}
\multicolumn{1}{|c|}{ The question ?? } \\
\hline What is the safety climate in the manager's commitment? \\
\hline What is the safety climate for the benefit of the worker? \\
\hline Which is the priority of the safety climate? \\
\hline What is the safety climate in the operating instructions? \\
\hline What is the safety climate in a supportive environment? \\
\hline What is the safety climate in worker participation? \\
\hline What is the safety climate as an individual priority? \\
\hline What is the safe climate in the work environment? \\
\hline What is the safety climate in the communication of health? \\
\hline What is the safety climate in managing change? \\
\hline What is the safety climate in the training of employees? \\
\hline What is the safe climate in safe behavior? \\
\hline What is the safety climate in common values? \\
\hline What is the adaptation of the safety climate to the system? \\
\hline What is the safety climate in accidents and accidents? \\
\hline What is the safe climate in the perception of risk? \\
\hline What is the safety climate in the management style? \\
\hline
\end{tabular}

\section{Working method}

The research is on one of the steel industries in ArcelorMittal Galati blast furnace $5\left(\mathrm{Vu}=2700 \mathrm{~m}^{3}\right)$ to determine the safety climate and provide a profile, [1].

In total, 57 subjects were asked to complete the questionnaire (all worked in the blast furnace section).

Their age ranged from 27-48 years and their working age, from 10-24 years. Of these, $88 \%$ are married, a total of 25 subunits, 20 subjects have general and secondary education, and 12 have higher education. The results are presented below (Table 3 ).

The processing is necessary for the creation of databases of personal data interviewed (Table 2) and average scores (weighted average) and frequencies relative to the relationship (1) are calculated.

\section{Management}

Table 3. Calculation for question no. 1

\begin{tabular}{|c|c|c|c|c|c|}
\hline \multicolumn{6}{|c|}{$\begin{array}{l}\text { What is the safety climate in the manager's } \\
\text { commitment? }\end{array}$} \\
\hline Scores & -2 & -1 & 0 & +1 & +2 \\
\hline Respondents & 2 & 4 & 2 & 15 & 34 \\
\hline
\end{tabular}

Formula of calculation, score 1(57 subjects):
$S_{1}=\frac{-2 \cdot 2-1 \cdot 4+0 \cdot 2+1 \cdot 15+2 \cdot 34}{57} \approx 1,315$

\section{Marketing}

Table 4. Calculation for question no. 2

Which is the priority of the safety climate?

\begin{tabular}{|l|c|c|c|c|c|}
\hline Scores & -2 & -1 & 0 & +1 & +2 \\
\hline Respondents & 2 & 1 & 7 & 15 & 32 \\
\hline
\end{tabular}

Formula of calculation score 2 (57 subjects):

$S_{2}=\frac{-2 \cdot 2-1 \cdot 1+0 \cdot 7+1 \cdot 15+2 \cdot 32}{57} \approx 1,263$

\section{Education}

Table 5. Calculation for question no. 3

What is the priority of the safety climate in education??

\begin{tabular}{|l|c|c|c|c|c|}
\hline Scores & -2 & -1 & 0 & +1 & +2 \\
\hline Respondents & 4 & 1 & 6 & 3 & 43 \\
\hline
\end{tabular}

Formula of calculation, score 1(57 subjects):

$S_{3}=\frac{-2 \cdot 4-1 \cdot 1+0 \cdot 6+1 \cdot 3+2 \cdot 43}{57} \approx 1,403$

\section{Safety instructions}

Table 6. Calculation for question no. 4 What is the safety climate in the operating instructions?

\begin{tabular}{|l|c|c|c|c|c|}
\hline Scores & -2 & -1 & 0 & +1 & +2 \\
\hline Respondents & 1 & 3 & 5 & 15 & 33 \\
\hline
\end{tabular}

Formula of calculation, score 1(57 subjects):

$S_{4}=\frac{-2 \cdot 1-1 \cdot 3+0 \cdot 5+1 \cdot 15+2 \cdot 33}{57} \approx 1,333$

\section{Costs}

Table 7. Calculation for question no. 5 What is the safety climate in a supportive environment?

\begin{tabular}{|l|c|c|c|c|c|}
\hline Scores & -2 & -1 & 0 & +1 & +2 \\
\hline Respondents & 2 & 2 & 1 & 10 & 42 \\
\hline
\end{tabular}


Formula of calculation, score 1(57 subjects):

$S_{5}=\frac{-2 \cdot 2-1 \cdot 2+0 \cdot 1+1 \cdot 10+2 \cdot 42}{57} \approx 1,543$

\section{Participation}

Table 8. Calculation for question no. 6

What is the safety climate in worker participation?
\begin{tabular}{|l|c|c|c|c|c|}
\hline Scores & -2 & -1 & 0 & +1 & +2 \\
\hline Respondents & 2 & 4 & 1 & 19 & 31 \\
\hline
\end{tabular}

Formula of calculation, score 1(57 subjects):

$S_{6}=\frac{-2 \cdot 2-1 \cdot 4+0 \cdot 1+1 \cdot 19+2 \cdot 31}{57} \approx 1,280$

\section{Individual priority and insecurity}

Table 9. Calculation for question no. 7

What is the safety climate as an individual priority?

\begin{tabular}{|l|c|c|c|c|c|}
\hline Scores & -2 & -1 & 0 & +1 & +2 \\
\hline Respondents & 0 & 1 & 2 & 3 & 51 \\
\hline
\end{tabular}

Formula of calculation, score 1(57 subjects):

$S_{7}=\frac{-2 \cdot 0-1 \cdot 1+0 \cdot 2+1 \cdot 3+2 \cdot 51}{57} \approx 1,824$

\section{Individual perception of risk}

Table 10. Calculation for question no. 8 What is the safety climate in perception of risk?

\begin{tabular}{|l|c|c|c|c|c|}
\hline Scores & -2 & -1 & 0 & +1 & +2 \\
\hline Respondents & 1 & 6 & 6 & 19 & 25 \\
\hline
\end{tabular}

Formula of calculation, score 1(57 subjects):

$S_{8}=\frac{-2 \cdot 1-1 \cdot 6+0 \cdot 6+1 \cdot 19+2 \cdot 25}{57} \approx 1,070$

\section{Working environment}

Table 11. Calculation for question no. 9

What is the safety climate in a supportive environment?

\begin{tabular}{|l|c|c|c|c|c|}
\hline Scores & -2 & -1 & 0 & +1 & +2 \\
\hline Respondents & 4 & 3 & 1 & 16 & 33 \\
\hline
\end{tabular}

Formula of calculation, score 1(57 subjects):

$S_{9}=\frac{-2 \cdot 4-1 \times 3+0 \cdot 1+1 \cdot 16+2 \cdot 33}{57} \approx 1,245$

\section{Common values}

Table 12. Calculation for question no. 10

What is the safety climate in common values?

\begin{tabular}{|l|c|c|c|c|c|}
\hline Scores & -2 & -1 & 0 & +1 & +2 \\
\hline Respondents & 4 & 8 & 3 & 20 & 18 \\
\hline
\end{tabular}

\begin{tabular}{|l|c|c|c|c|c|}
\hline Respondents & 4 & 8 & 3 & 20 & 18 \\
\hline
\end{tabular}

Formula of calculation, score 1(57 subjects):

$S_{10}=\frac{-2 \cdot 4-1 \times 8+0 \times 3+1 \cdot 20+2 \times 18}{57} \approx 0,701$

\section{Management of change}

Table 13. Calculation for question no. 11

What is the safety climate in management of change?

\begin{tabular}{|l|c|c|c|c|c|}
\hline Scores & -2 & -1 & 0 & +1 & +2 \\
\hline
\end{tabular}

\begin{tabular}{|l|l|l|l|l|l|}
\hline Respondents & 2 & 4 & 2 & 15 & 34 \\
\hline
\end{tabular}

Formula of calculation, score 1(57 subjects):

$S_{11}=\frac{-2 \cdot 2-1 \times 4+0 \times 2+1 \cdot 15+2 \cdot 34}{57}=0,719$

\section{Public perception}

Table 14. Calculation for question no. 12

What is the safety climate in the Public perception?

\begin{tabular}{|l|c|c|c|c|c|}
\hline Scores & -2 & -1 & 0 & +1 & +2 \\
\hline Respondents & 6 & 6 & 2 & 24 & 19 \\
\hline
\end{tabular}

Formula of calculation, score 1(57 subjects):

$S_{12}=\frac{-2 \cdot 6-1 \cdot 6+0 \cdot 2+1 \cdot 24+2 \cdot 19}{57} \approx 0,771$

\section{Competence and certification}

Table 15. Calculation for question no. 13

What is the climate in the competence and certification?

\begin{tabular}{|l|c|c|c|c|c|}
\hline Scores & -2 & -1 & 0 & +1 & +2 \\
\hline Respondents & 5 & 2 & 2 & 28 & 20 \\
\hline
\end{tabular}

Formula of calculation, score 1(57 subjects):

$S_{13}=\frac{-2 \cdot 5-1 \cdot 2+0 \cdot 2+1 \cdot 28+2 \cdot 20}{57} \approx 0,982$ 


\section{Cooperation}

Table 16. Calculation for question no. 14

What is the safety climate in the communication of health?

\begin{tabular}{|l|c|c|c|c|c|}
\hline Scores & -2 & -1 & 0 & +1 & +2 \\
\hline Respondents & 9 & 12 & 6 & 15 & 16 \\
\hline
\end{tabular}

Formula of calculation, score 1(57 subjects):

$S_{14}=\frac{-2 \times 9-1 \times 12+0 \times 6+1 \times 15+2 \times 16}{57} \approx 0,298$

\section{Safe behavior}

Table 17. Calculation for question no. 15

What is the adaptation of the safety climate to the system?

\begin{tabular}{|l|c|c|c|c|c|}
\hline Scores & -2 & -1 & 0 & +1 & +2 \\
\hline Respondents & 2 & 6 & 6 & 22 & 21 \\
\hline
\end{tabular}

Formula of calculation, score 1(57 subjects):

$S_{15}=\frac{-2 \cdot 2-1 \cdot 6+0 \cdot 6+1 \cdot 22+2 \cdot 21}{57} \approx 0,947$

\section{Incidents and accidents}

Table 18. Calculation for question no. 16 What is the safety climate in accidents and accidents?

\begin{tabular}{|l|c|c|c|c|c|}
\hline Scores & -2 & -1 & 0 & +1 & +2 \\
\hline Respondents & 8 & 11 & 6 & 22 & 10 \\
\hline
\end{tabular}

Formula of calculation, score 1(57 subjects):

$S_{16}=\frac{-2 \times 8-1 \times 11+0 \times 6+1 \times 22+2 \times 10}{57} \approx 0,263$

\section{Implementation of the safety system}

Table 19. Calculation for question no. 17

What is the safety climate in the management style??
\begin{tabular}{|l|c|c|c|c|c|}
\hline Scores & -2 & -1 & 0 & +1 & +2 \\
\hline Respondents & 3 & 3 & 1 & 18 & 32 \\
\hline
\end{tabular}

Formula of calculation, score 1(57 subjects):

$S_{17}=\frac{-2 \cdot 3-1 \cdot 3+0 \cdot 1+1 \cdot 18+2 \cdot 32}{57} \approx 1,280$

The average score values for each statement are presented in the table below: - average scores calculated on a scale of -2 (Total disagreement) to 2 (Total agreement). The results are presented in the Table 20:
Table 20

\begin{tabular}{|c|l|c|c|}
\hline No. & \multicolumn{1}{|c|}{ The field of evaluation } & $\begin{array}{c}\text { Method of } \\
\text { evaluation }\end{array}$ & $\begin{array}{c}\text { Average } \\
\text { value }\end{array}$ \\
\hline 1 & Management & Checklist & 1.315 \\
\hline 2 & Marketing & Checklist & 1.263 \\
\hline 3 & Education & Checklist & 1.403 \\
\hline 4 & Safety instructions & Checklist & 1.333 \\
\hline 5 & Costs & Checklist & 1.543 \\
\hline 6 & Participation & Checklist & 1.280 \\
\hline 7 & Individual priority and insecurity & Checklist & 1.842 \\
\hline 8 & Individual perception of risk & Checklist & 1.070 \\
\hline 9 & Working environment & Checklist & 1.245 \\
\hline 10 & Common values & Checklist & 0.701 \\
\hline 11 & Management of change & Checklist & 0.719 \\
\hline 12 & Public perception & Checklist & 0.771 \\
\hline 13 & Competence and certification & Checklist & 0.982 \\
\hline 14 & Cooperation & Checklist & 0.298 \\
\hline 15 & Safe behavior & Checklist & 0.947 \\
\hline 16 & Incidents and accidents & Checklist & 0.263 \\
\hline 17 & Implementation the safety system & Checklist & 1.280 \\
\hline
\end{tabular}

The average score values for each statement are presented in the table below: - average scores calculated on a scale of -2 (Total disagreement) to 2 (Total agreement).

The data that is arranged in columns or rows in a worksheet can be graphically represented in a radar chart. Radar diagrams compare the aggregate values of several data series.

The total score: Based on the calculated scores, determining the total score middle, as the arithmetic mean of the scores of the $n(n=17)$ characteristics:

$$
S_{T}=\frac{1}{n} \sum_{1=1}^{n} S_{i}=\frac{17,536}{17}=\mathbf{1}, \mathbf{0 3 1 5 3}
$$




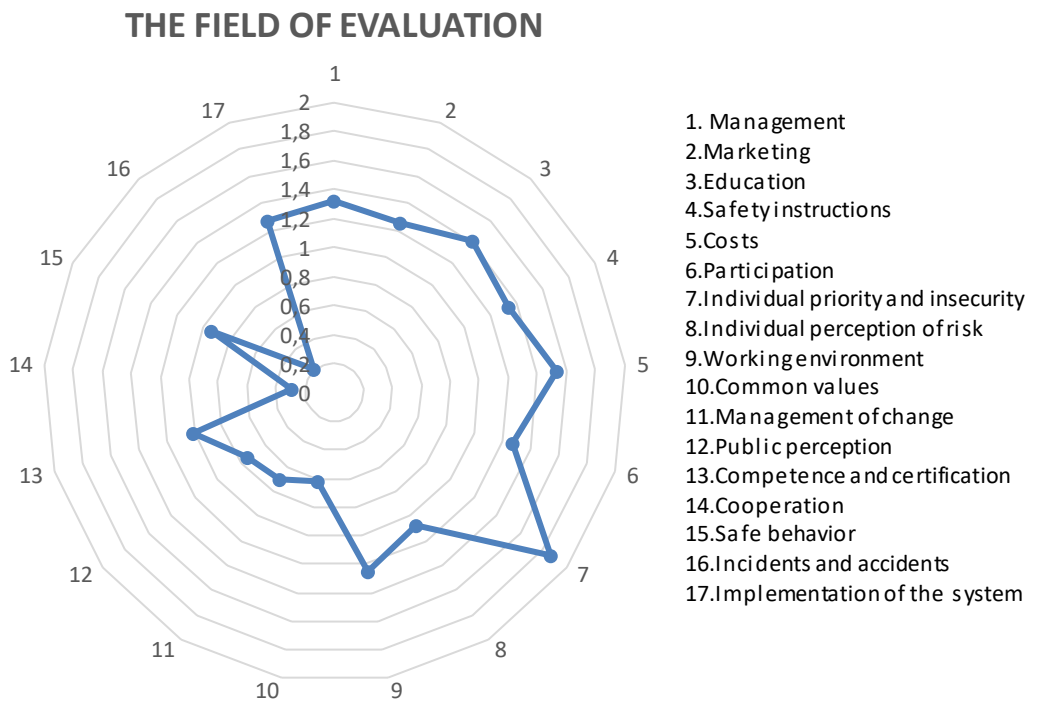

Fig. 1. Graphic diagram of the safety climate profile

\section{Conclusions}

Management's decision regarding safety issues, conducting proactive activities regarding incidents, immediate reform of safety issues, lead to the creation of a safe and healthy work climate (overall average score ST = 1.03153). Research has shown that the safety climate is on average in the industry.

1. The employees criticized the concerns regarding the non-observance of the safety instructions from some employees;

2. On the other hand, in 7 areas, they are below the average of evaluation, namely, areas of incidents and accidents $(\approx 0.263)$, cooperation $(\approx 0.298)$ common values $(\approx 0.701)$ change management $(\approx$ $0.719)$ and leadership style (0.771) which need to be further analysed and urgent measures taken to address the shortcomings;

3. On the opposite side, based on the analysis, it turns out that there are very well-developed areas, such as, individual priority (1.824), costs (1.543), education and training (1.403) and management (1.315);

4. The rest of the analysed areas (7) are above average;
5. As measures the interest of the services responsible for the safety on behalf of the employees and of the management is proposed;

6. Research has shown that the safety climate is on average in the industry. In some areas of the security climate, such as the commitment of management, communication, security priority, security regulations, support environment, participation, individual priority, individual perception of risk, working environment, achievement of the safety climate are approximately in average. In other areas, including common values, change management, leadership style, competence and training, cooperation, safe behaviour, incidents and accidents, the score is poor.

\section{References}

[1]. ***, Documentation of ArcelorMittal Galati.

[2]. ***, Likert Scale, http://en.wikipedia.org.

[3]. Adrian Vasiliu, Occupational health and safety management, Electronic course, UGAL Galati, 2018.

[4]. Oleg Bulgaru, Statistical applications in sociological research, Course support, ISBN 978-9975-71-XXX-X, USM, Chisinau, 2018.

[5]. ***, OSH: 2001 - Guiding principles for occupational safety and health management systems.

[6]. ***, OHSAS 18002: Implementation guide of OHSAS 18001, Likert Scale, http://en.wikipedia.org. 